\title{
Use of optical magnification and microsurgical technique in general surgery
}

\section{Valerio D'Orazi ${ }^{1}$, Andrea Ortensi ${ }^{2}$}

1. Department of Surgical Sciences, "Sapienza” University of Rome, Italy

2. Department of General Microsurgery and Hand Surgery, "Fabia Mater" Hospital, Rome, Italy

\section{EDITORIAL}

Please cite this paper as: D'Orazi V, Ortensi A. Use of optical magnification and microsurgical technique in general surgery. AMJ 2017;10(12):989-992.

https://doi.org/10.21767/AMJ.2017.3196

Corresponding Author:

Valerio D'Orazi

Viale Regina Elena 324, 00161, Rome, Italy

Email: valerio.dorazi@uniroma1.it

The full benefits of magnified vision in all disciplines of videoassisted surgery are well known and appreciated for many years. The use of microsurgery in limb transplants and microvascular free flaps has now been standardized and used for many years..$^{1-4}$ On the other hand, a special emphasis must be put on the advantage that can be achieved by the use of optical magnification during microsurgery operations, in general surgery.

The purpose of this work is to give some personal insights into experience using microsurgery in a surgical department, particularly in thyroid and parathyroid surgery, parotid and submandibular surgery, peripheral nerve surgery and andrological microsurgery that is all areas of general surgery which have in common the need for conservation and preservation of important nerve structures.

Over the past 50 years we have seen significant technological innovations in the field of thyroid and parathyroid surgery, with a significant reduction in mortality and complications such as lesions of the laryngeal nerves and hypoparathyroidism..$^{5-7}$ Complications in thyroid surgery can be reduced by proper anatomical knowledge of the neck and using precise surgical technique. ${ }^{8,9}$ In the last 40 years there are only a few publications in the literature about the use of microsurgery in thyroid surgery, and all emphasize the concept that microsurgery improves surgical results especially in reinterventions and in lymphadenectomy. ${ }^{8,10-18}$ We recently published a paper in which thyroid complications are analysed from a large number of patients using microsurgical technique and optical magnification. ${ }^{19}$ In this study we concluded that using the approach proposed can reduce the complications both with regard to hypoparathyroidism and to recurrent nerve paralysis. Moreover, using only a microscope can repair any accidental intraoperative injury of the inferior laryngeal nerve. ${ }^{19,20}$ This study strongly supports the use of optical magnification during microsurgery operations, in general surgery. In addition, to more accurately visualize its enlarged vision through the loupes in thyroid surgery, we have recently developed a video prototype that provides better results in terms of video quality, providing both surgical and teaching aids. ${ }^{21}$

In major salivary glands surgery, it is essential to identify and preserve the facial nerve in parotid surgery and lingual and hypoglossal nerves in sub-mandibular surgery. The risk of transient facial nerve dysfunction is estimated around $20-40$ per cent, while persistent facial nerve palsy occurs in 0-4 per cent of patients. ${ }^{22-25}$ Rarely the facial nerve can be affected by a schwannoma, in that case the use of microsurgery is essential to limit the incidence of injuries. ${ }^{24}$ Familiarity with microsurgery, allows one to perform an immediate reconstruction of the nerve due to accidental injury during surgery and thus would avoid a difficult reoperation, moreover burdened by high failure rates. Therefore, functional and cosmetic deficits associated with the accidental injury of these nerves should induce every surgeon, treating these pathologies, to use microsurgical technique and loupes magnification. In this regard, some authors have recently reported a reduction of post-operative complications and facial paralysis by using bipolar dissection technique and the study by Nicoli et al. ${ }^{26}$ confirmed the low morbidity associated with superficial parotidectomy and total conservative parotidectomy using microsurgical techniques. $^{25,26}$

The use of microsurgery is an established procedure worldwide for peripheral nerve injury. Microsurgery, in 
fact, is essential in the treatment of iatrogenic injury (facial nerve, recurrent laryngeal nerve, sciatic nerve, femoral nerve, tibial nerve), in traumatic instances and in inguinal pain syndrome (chronic orchialgia, nerve damage as a result of hernia repair, orchidopexy and varicocele repair). Chronic testicular pain is defined as unilateral or bilateral scrotum pain lasting at least three months, and is a disease of difficult therapeutic resolution. When medical therapy fails, the only therapeutic resolution is represented by the microsurgical denervation of the spermatic cord. The first operation of this kind was carried out about 40 years ago, and since then numerous studies have been published demonstrating the efficacy of this therapy. ${ }^{27}$ Recently, the robot has been used for the treatment of chronic testicular pain reporting similar results to those already published using microsurgery.

Robotic technology lends itself as a particularly useful tool for other andrological microsurgical interventions such as vasectomy reversal. ${ }^{28}$ In a recent review Korzadeh reported that inguinal hernia repair with use of mesh in bilateral open and/or laparoscopic repair may cause male infertility for the obstruction and/or damage to the cord and the vessels. ${ }^{29}$ It is quite innovative that, a recent article proposes the use of an operating microscope in the treatment of inguinal hernia, especially when employed by an urologist performing simultaneous operations for varicocele or surgical procedures on spermatic cord or testis. According to the authors, the use of microsurgery is crucial to minimize surgical complications. ${ }^{30}$ Furthermore, it's very interesting that the authors believe that inguinal hernia repair using microsurgical technique represents a valuable aid to safeguard injury to nerve structures such as ilioinguinal and genito-femoral nerve, arterial vessels and vas deferens; such treatment has the potential to minimize the risk of hematoma, infection, vasal obstruction, sensory loss and chronic post-herniorrhaphy pain. In regard to the use of magnification in hernia surgery repair, our group systematically uses microsurgery also in inguinal and andrological surgeries by adopting loupes 4.5 magnification and reserving the use of the microscope for vas deferens surgery and to the difficult reconstructions of the seminal pathways in men with obstructive azoospermia (OA).

Surgery for peripheral nerve sheath tumours (PNST), represented by schwannomas and neurofibromas, is particularly delicate and should be performed only in selected centers using microsurgery. Guya et al., in a recent clinical article, presented one of the largest single-institution series of symptomatic, surgically treated PNSTs, performing surgeries observing the rules of microsurgery. ${ }^{31}$ In schwannomas surgery, generally almost all nerve fascicles can be detached from the tumour and left intact, with the exception of one or two fascicles entering into the tumour, usually lacking in functionality that must necessarily be sacrificed. Neurofibromas, instead, typically had two or more entering and exiting fascicles and required more accurate dissection, following the same rules used in the removal of schwannomas. ${ }^{31}$ This is one of the main reasons why it is more difficult to remove a neurofibroma without damaging the nerve than a schwannoma, therefore a preoperative diagnosis is essential for better surgical planning. Adani in an interesting study published recently, has redefined what should be the correct diagnostic and therapeutic approach in 34 schwannomas operated in a period of 16 years, and evaluated short- and long term neurological deficits. The authors highlight that the use of microsurgery associated with suitable clinical experience is critical in surgery of nerve tumours, to achieve excellent functional results. $^{32}$ Ultimately, the proper surgical approach of PNSTs (neurofibromas and schwannomas) is tumour removal from the involved nerve under magnification using microsurgical technique. ${ }^{33-36}$

Andrological microsurgery plays an important role especially in patients with non-obstructive azoospermia (NOA), where microscopic testicular sperm extraction (micro-TESE) is a valid support for assisted reproduction techniques (ART). ${ }^{37}$ In the management of male infertility, the use of microsurgery is a widespread and established procedure in many diseases, like varicocele and obstructive OA. ${ }^{38-40}$

Microsurgery and magnification can be used with undoubted advantages in several surgical interventions, but requires expertise with microscopic instrumentation and optical magnification. The operator can only acquire these skills after long periods of clinical-experimental training and continuously maintaining training in the technique, possibly participating in microsurgery courses aimed at the use of optical magnification devices and a microsurgical instrument. It is essential that the surgeon, especially if young, is provided with appropriate ongoing training courses, since occasional surgery using microsurgery can make surgical performance difficult and be risky for the patient.

Decreasing the complications and improving patient quality of life should represent the criteria of feasibility and usefulness of each surgical technique and microsurgery definitely presents the right qualities to achieve those objectives. 


\section{References}

1. Germain MA, Legagneux J. Vascular microsurgery and progress of free flap surgery. Ann Chir. 2001;126:960-968.

2. Holm C, Mayr M, Hoefter E, et al. Assessment of the patency of microvascular anastomoses using microscopeintegrated near-infrared angiography: A preliminary study. Microsurgery. 2009;29:509-514.

3. Prucz RB, Friedrich JB. Upper extremity replantation: current concepts. Plast Reconstr Surg. 2014;133(2):33342.

4. Saint-Cyr M, Wong C, Buchel EW, et al. Free tissue transfers and replantation. Plast Reconstr Surg. 2012;130(6):858e-878e.

5. Gómez-Ramírez J, Sitges-Serra A, Moreno-Llorente $P$, et al. Mortality after thyroid surgery, insignificant or still an issue? Langenbecks Arch Surg. 2015;400:517-522.

6. Christou N, Mathonnet M. Complications after total thyroidectomy. J Visc Surg. 2013;150:249-256.

7. Selberherr A, Scheuba C, Riss $P$, et al. Postoperative hypoparathyroidism after thyroidectomy: Efficient and cost-effective diagnosis and treatment. Surgery. 2015;157:349-353.

8. Williams SP, Wilkie MD, Tahery J. Microscope-assisted thyroidectomy: Our experience in one hundred and twenty-one consecutive cases. Clin Otolaryngol. 2014;39:289-315.

9. Lahey $\mathrm{FH}$. Routine dissection and demonstration of recurrent laryngeal nerve in subtotal thyroidectomy. Surg Gyn \& Obst. 1938;66:775.

10. Attie JN, Khafif RA. Preservation of parathyroid glands during total thyroidectomy. Improved technic utilizing microsurgery. Am J Surg. 1975;130:399-404.

11. Cavallaro G, Taranto G, Chiofalo MG, et al. Usefulness of microsurgery to isolation of recurrent laryngeal nerve and parathyroid during thyroidectomy operations. Microsurgery. 1998;18:460-461.

12. Nielsen TR, Andreassen UK, Brown CL, et al. Microsurgical technique in thyroid surgery. A 10-year experience. Laryngol Otol. 1998;112:556-560.

13. Doikov IY, Yovchev IP, Konsulov SS. Microsurgical technique as a method for prevention of recurrent laryngeal nerve injury in thyroid surgery. Review of seven consecutive cases. Folia Med (Plovdiv). 2001;43:5-9.

14. Testini M, Nacchiero $M$, Piccinni $G$, et al. Total thyroidectomy is improved by loupe magnification. Microsurgery. 2004;24:39-42.

15. Seven H, Calis AB, Vural C, et al. Microscopic thyroidectomy: a prospective controlled trial. Eur Arch Otorhinolaryngol. 2005;262:41-44.

16. Pata G, Casella C, Mittempergher F, et al. Loupe magnification reduces postoperative hypocalcemia after total thyroidectomy. Am Surg. 2010;76:1345-1350.

17. Davidson BJ, Guardiani E, Wang A. Adopting the operating microscope in thyroid surgery: safety, efficiency, and ergonomics. Head Neck. 2010;32:154159.

18. Alshahrani MA, Alzahrani FR, Alghamdi AS, et al. Impact of neuromonitoring of recurrent laryngeal nerve and surgical loupes on the outcome of thyroidectomy. Saudi Med J. 2013;34:824-828.

19. D'Orazi V, Panunzi A, Di Lorenzo E, et al. Use of loupes magnification and microsurgical technique in thyroid surgery: ten years' experience in a single center. G Chir. 2016;37(3):101-107.

20. Quadros LS, Prasanna LC, D'Souza AS, et al. Unilateral anatomical variation of the ansa cervicalis. Australas Med J. 2015;8(5):170-173.

21. Ortensi A, Panunzi A, Trombetta $S$, et al. Advancement of thyroid surgery video recording: A comparison between two full HD head mounted video cameras. Int J Surg. 2017;41(Suppl 1):S65-S69.

22. Knopf A, Szyper M, Mansour N, et al. A critical review of 20 years of parotid gland surgery. Acta Otolaryngol. 2016;136:711-716.

23. Mantsopoulos K, Koch M, Klintworth $\mathrm{N}$, et al. Evolution and changing trends in surgery for benign parotid tumors. Laryngoscope. 2015;125:122-127.

24. Fini G, Leonardi A, Mici E, et al. Schwannoma of the parotid gland. Case report. Ann Ital Chir. 2015;86:1-4.

25. Knopf A, Heiser C, Karasoy Ö, et al. Bipolar dissection technique in parotid gland surgery. Acta Otolaryngol 2017;137(11):1210-1214.

26. Nicoli F, D'Ambrosia C, Lazzeri D, et al. Microsurgical dissection of facial nerve in parotidectomy: a discussion of techniques and long-term results. Gland Surg. 2017;6(4):308-314.

27. Devine CJ Jr, Schellhammer PF. The use of microsurgical denervation of the spermatic cord for orchialgia. Trans Am Assoc Genitourin Surg. 1978;70:149-51.

28. Kavoussi P, Calixte N, Brahmbhatt J, et al. Robotassisted microsurgery for chronic orchialgia. Transl Androl Urol. 2017;6(Suppl 1):S6-S9.

29. Kordzadeh A, Liu MO, Jayanthi NV. Male infertility following inguinal hernia repair: a systematic review and pooled analysis. Hernia. 2017;21(1):1-7.

30. Schulster ML, Cohn MR, Najari BB, et al. Microsurgically assisted inguinal hernia repair and simultaneous male fertility procedures: Rationale, technique and outcomes. J Urol. 2017;198(5)1168-74. DOI: 10.1016/j.juro.2017.06.072.

31. Guha D, Davidson B, Nadi M, et al. Management of 
peripheral nerve sheath tumors: 17 years of experience at Toronto Western Hospital. J Neurosurg. 2017;7:1-9.

32. Adani R, Tarallo L, Mugnai R, et al. Schwannomas of the upper extremity: analysis of 34 cases. Acta Neurochir (Wien). 2014;156(12):2325-30.

33. D'Orazi V, Venditto T, Panunzi A, et al. Misdiagnosis of plexiform neurofibroma of the medial plantar nerve: case report. Foot (Edinb). 2014;24(3):143-5.

34. Caltabiano R, Magro G, Polizzi A, et al. A mosaic pattern of INI1/SMARCB1 protein expression distinguishes Schwannomatosis and NF2-associated peripheral schwannomas from solitary peripheral schwannomas and NF2-associated vestibular schwannomas. Childs Nerv Syst. 2017;33(6):933-940.

35. Ruggieri M, Polizzi A, Spalice A, et al. The natural history of spinal neurofibromatosis: a critical review of clinical and genetic features. Clin Genet. 2015;87(5):401-10.

36. Ruggieri M, Polizzi A, Salpietro V, et al. Spinal neurofibromatosis with central nervous system involvement in a set of twin girls and a boy: further expansion of the phenotype. Neuropediatrics. 2013;44(5):239-44.

37. Flannigan R, Bach PV, Schlegel PN. Microdissection testicular sperm extraction. Transl Androl Urol. 2017;6(4):745-752.

38. Tatem AJ, Brannigan RE. The role of microsurgical varicocelectomy in treating male infertility. Transl Androl Urol. 2017;6(4):722-729.

39. Chen XF, Chen B, Liu W, et al. Microsurgical vasoepididymostomy for patients with infectious obstructive azoospermia: cause, outcome, and associated factors. Asian J Androl. 2016;18(5):759-62.

40. Bo S, Hongmei S, Zhenhui $H$, et al. Effectiveness of two kinds of medicine on non-obstructive azoospermia. Australas Med J. 2017;10(9):785-788.

\section{PEER REVIEW}

Not commissioned. Externally peer reviewed.

\section{CONFLICTS OF INTEREST}

The authors declare that they have no competing interests.

\section{FUNDING}

None 